\title{
Rat Models of Spinal Cord Injury Provide Valuable Insight to Understand the Mechanism and Patho- physiology of Spinal Cord Injury
}

\author{
Atiq Hassan ${ }^{1,2^{*}}$ \\ ${ }^{1}$ Department of Health and Rehabilitation Sciences, School of Health Technology and Management, Stony \\ Brook University, Life Sciences Building, Stony Brook, NY, USA \\ ${ }^{2}$ Biomedical Sciences, WCVM, University of Saskatchewan, Saskatoon SK, Canada \\ *Corresponding author: Atiq Hassan, Department of Health and Rehabilitation Sciences, School of Health \\ Technology and Management, Stony Brook University. Life Sciences Building, Rm: 121, 100 Nicolls Road, \\ Stony Brook, NY 11794, USA, Tel: +1 6316323696; E-mail: atiqhassan@gmail.com, atiq.hassan@usask.ca
}

Received Date: 09 November, 2017; Accepted Date: 23 January, 2018; Published Date: 07 February, 2018

\begin{abstract}
Spinal Cord Injury (SCI) is a serious devastating global problem, which mostly affects young persons aged 16 to 30 . SCI damages axonal pathways and interrupts synaptic transmission between brain and spinal cord. SCI in general can be classified as either complete injuries or incomplete injuries. Each type of SCI occurs in two phases, primary and secondary phase of SCI. The causes of SCI are diverse in origin and can result from contusion, compression, penetrations or maceration of the spinal cord. A variety of animal models including dogs, cats, guinea pig, primates and rodents have been developed to examine the mechanisms, pathophysiology and functional deficits following SCI, and also to test intervention strategies to develop effective therapies for the treatment of SCI. The most commonly used rat models of spinal cord injuries are transection models, compression models, contusion models and chemically-induced models. There is no single model that has dominated in the field of SCI research and each model has advantages and disadvantages. This review discusses the advantages and disadvantages of rat models of experimental SCI and knowledge gained from these rat models to understand the mechanisms, pathophysiology of SCI.
\end{abstract}

\section{Keywords}

Axonal Regeneration; Pathophysiology; Rat Model; Spinal Cord Injury

\section{Introduction}

The spinal cord contains neural circuitry and motoneurons in the central core of grey matter and axonal pathways in the surrounding white matter. Many of the consequences of Spinal Cord Injury arise from the interruption of the white matter axonal connections between the brain and spinal cord, resulting in paresis or paralysis and loss of sensation to the different parts of the body controlled by the spinal cord segments below the injury. An injury at the cervical level may cause paralysis of both arms and legs resulting in quadriplegia, whereas lower injuries may affect only the lower part of the body causing paraplegia $[1,2]$. Spinal cord injuries also can lead to other complications, including respiratory insufficiency, the leading cause of death in patients with high-cervical spinal cord injuries, sexual impotence, muscle spasticity and loss of bladder and bowel control [2-6]. The physical disabilities associated with SCI vary greatly depending on the type and severity of the injury, the level of the spinal cord at which injury occurs, and the nerve fibers pathways that are damaged due to injury.

Spinal cord injuries in general can be classified as either complete injuries or incomplete injuries [7]. With complete SCI, there is total loss of sensation and voluntary movement below the level of injury. Incomplete SCI is more common and is characterized by some degree of sensation and movement below the level of injury. It is possible that the classification of the injury might change during recovery [8]. Each type of SCI occurs in two phases primary and secondary phase of SCI, discussed in detail in the following Section.

\section{Phases of Spinal Cord Injury}

There are two mechanisms by which SCI damages the spinal 
cord, a primary or mechanical injury and a secondary injury process. Primary injury causes damage locally, namely in the area of the vertebral fracture, and it is characterized by acute hemorrhage and ischemia. Secondary damage is mediated through multiple processes, including inflammation, apoptotic cell death, excitotoxicity within the first week following SCI, causing further destruction of neuronal and non-neuronal cells [9]. Secondary mechanisms of injury exacerbate lesion size and severity, which increases the functional deficits [10]. The identification and understanding of mechanisms which initiate and sustain the inflammatory response, apoptosis, excitotoxicity, could help us to develop new treatment strategies which prevent or reduce this secondary damage and improve functional recovery [11]. These primary and secondary mechanisms of spinal cord damage are described in more detail below.

\section{Primary injury}

The causes of SCI are diverse in origin and can induced by contusion, compression, penetrations or maceration of the spinal cord $[12,13]$. Acute SCI is a bi-phasic process involving primary and secondary mechanisms. The primary injury to the spinal cord occurs at the instant of impact and is commonly due to mechanical damage. This damage can be contusion resulting in cavity formation, compression caused by increased pressure to the spinal tissue, laceration from sharp bone fragments or foreign objects, and shearing caused by bullets [14]. The most common cause of primary SCI is vertebral fracture, which typically tears the spinal cord tissues and produces characteristic damage of the gray and white matter [15-17]. In addition to disrupting axons, mechanical damage causes death of neurons, oligodendrocytes and astrocytes, and endothelial cells located at the site of the lesion. Disruption of blood vessels also causes hemorrhage [17].

\section{Secondary injury}

A progressive degeneration occurs immediately after the primary injury, which is called as secondary injury, may last for days, weeks or months. It is a highly complex process and involves numerous mechanisms including ischemia, inflammation, generation of free radical species, necrosis and apoptosis, and dysregulation of ionic hemostasis [13].

Ischemia: SCI damages the blood vessels and induce changes in spinal cord blood flow at the systemic and local level and a major reduction in blood flow (ischemia) occurs at the lesion site [18]. Damage to blood vessels causing oxygen and nutritional insufficiency can lead to neuronal apoptosis [19]. In addition to this there are several mechanisms that are responsible for ischemia following SCI, including vasospasm due to release of vasoactive amines, hemorrhages, endothelial swelling and thrombosis through platelet aggregation [10,20-23].

Inflammation: Following SCI, the blood brain barrier is physically broken, causing an increase in permeability, allowing the cells from the blood to invade and initiate the inflammatory re- sponse. This contributes to secondary damage in the spinal cord $[24,25]$. Inflammation is a universal defense response to tissue injury and is initiated after SCI [13]. The inflammatory response includes the invasion of inflammatory cells (neutrophils, T-lymphocytes), and macrophages, and release of the chemicals from the cells such as cytokines, prostaglandins, interleukins. These neutrophils, T-lymphocytes, macrophages and chemicals release from the cells (cytokines, prostaglandins, interleukins) mediate the inflammatory response and contribute to further tissue damage [17].

Excitotoxicity: Ionic homeostasis is necessary to maintain the calcium gradient across the cell membrane. This homeostasis of calcium ion gradients can be disrupted due to mechanical changes in the microvasculature and hemorrhage, which can lead to increased intracellular calcium ion concentration, causing the depolarization of the cell membrane [26-28]. This in turn can cause increased release of the most prevalent excitatory neurotransmitter, glutamate, into the synaptic cleft. Regulation of glutamate concentration is necessary to maintain the normal cellular function of neurons. Glutamate activates NMDA receptors, which allow massive influx of calcium ions into the cell. This triggers calcium-induced calcium release from the intracellular calcium store into the cytoplasm $[13,29]$. Elevated concentration of calcium ions in cytosol can trigger many calcium-dependent intracellular pathways and activate the lytic enzymes such as proteases, caspases, caplains, phospholipases, endonucleases, and lipoxygenase that alter cellular metabolism and cause dysregulation of mitochondrial oxidative phosphorylation leading to apoptotic cell death of neurons [26,28-30].

Apoptotic cell death: Apoptosis is a programmed cell death and it occurs around the lesion epicenter as well as within the areas of Wallerian degeneration in both ascending and descending tracts of white matter in the spinal cord [31]. Apoptosis has been identified in the spinal cord of rats and humans after SCI [3135]. It may occur as a result of adverse changes in the cellular environment as described above, resulting in axonal demyelination or as a result of Wallerian degeneration or by a combination of both [9,30,36-38]. After traumatic SCI in rats, apoptotic pathways are activated in neurons in the first hours after injury, and hours to days later in oligodendrocytes adjacent to and distant from the injury site $[32,39,40]$.

\section{Experimental Rodent Models of Spinal Cord Injury}

A variety of animal models including dogs, cats, guinea pig, primates and rodents have been developed to examine the mechanisms, pathophysiology and functional deficits following SCI, and also to test intervention strategies to develop effective therapies for the treatment of SCI. Rodents, such as rats and mice, have emerged as the main animal used in Spinal Cord Injury research, making up $90 \%$ of laboratory animals used in SCI research [41]. The advantages of using rodents include low costs 
Citation: Hassan A (2018) Rat Models of Spinal Cord Injury Provide Valuable Insight to Understand the Mechanism and Pathophysiology of Spinal Cord Injury. Curr Adv Neurol Neurol Disord 2018: 1-6. DOI: https://doi.org/10.29199/2637-6997/CANN-102018.

of purchasing and housing, as well as a short life span.

Rat models of SCI are the most widely used to study the mechanism and consequences of SCI because many of the morphological, biochemical, functional and behavioural changes that occur after SCI are similar to those seen in humans after SCI. The most commonly used rat models of spinal cord injuries are transection models, compression models, contusion models and chemically-induced models $[41,42]$. Compression and contusion injuries are most common in humans [41,42]. There is no single model that has dominated in the field of SCI research and each model has advantages and disadvantages.

\section{Contusion}

The production of an experimental spinal contusion injury is the most commonly used method because these injuries are clinically relevance to SCI occurring in humans [14]. This method relies on an impactor device that hits the spinal cord and produces either a defined force upon or a defined displacement of the cord. The contusion model of Spinal Cord Injury was first developed by Allen, who used a weight drop technique on the spinal cord in dogs [43]. This weight drop technique was later developed in rats to deliver a blunt contusive force to the spinal cord [44]. This weight drop technique is now widely used to produce contusion models of SCI, and several devices are designed to produce blunt contusive injury in animals. The New York University (NYU) Impactor is a sophisticated device introduced by Gruner in 1992 [45]. The NYU Impactor drops a 10-gram weight from 6.25, $12.5,25$ or $50 \mathrm{~mm}$ directly onto the exposed spinal cord. This weight impacts the spinal cord with a defined force and induces contusion injury quickly. A modified version of weight drop impactor was introduced at the Ohio State University Spinal Cord Research Centre, where researchers developed the Ohio State University (OSU) electromechanical spinal cord impactor, a device which induces the injury by solenoid-controlled air cylinder [46]. The severity of injury depends on the velocity and height of weight drop onto the exposed spinal cord. Both NYU and OSU impactors apply and remove force within one second and so induce contusion quickly. These impactors produce contusion injury in animals that allow to study the mechanism of secondary damage to spinal cord.

The majority of SCI in humans is contusive in nature and a contusion model of SCI is generally accepted as being clinically relevant to SCI $[47,48]$. Contusion SCI models are ideal for study of the pathologies and mechanisms of secondary damage to the spinal cord [49]. Moreover, contusion models of SCI have been useful for the study of neuroprotective strategies, plasticity and demyelination after SCI $[12,14]$. Nevertheless, contusion models do not completely mimic clinical occurrences of SCI in that the contusion models require pre-injury laminectomy, including surgical removal of muscles, ligaments and part of the vertebra [50]. The technique used to produce contusion injury by impactor also induces some undesirable damage to soft tissue in surrounding areas [50]. Finally, the contusive injury model is not a good model for investigation of axonal regeneration due to incomplete nature of the injury and the complexity of the tracts [51,52].

\section{Compression}

The compression model of SCI delivers a sustained and static force to the spinal cord for a specific duration of time, in contrast to the contusion models that deliver a single rapid blunt force to the exposed spinal cord [53]. Compression models of SCI are highly reproducible and useful to study the secondary mechanisms and pathophysiology following SCI. They are used to examine the effect of potential therapeutic agents to protect neuronal and non-neuronal cell loss due to secondary injury, with the aim to limit the severity of injury and minimize functional deficit following SCI. Compression models produce a glial scar similar to those seen in human SCI [54]. Compression can be produced by balloon compression clip compression or a forceps compression [53].

Tarlov and his colleagues developed the balloon catheter technique, the first compression model of SCI [55]. The balloon catheter is a catheter placed within the spinal canal, and when expanded, can induce a slowly developing compression such as seen in spinal tumour. The severity of injury produced by balloon catheter can be controlled by the pressure of inflated balloon and duration of application or by both [56,57]. This balloon catheter technique produces slow compression SCI, and allows studying the mechanism of SCI produce by spinal tumour.

Rivilin and Tator developed a calibration clip compression model of SCI $[54,58]$. In this model, the spinal cord is exposed by performing a laminectomy and the blades of an aneurysm clip are placed on both dorsal and ventral surfaces of spinal cord. Force is applied by closing the clip to compressing the spinal cord in a dorso-ventral direction [12,59]. The severity of the injury produced by calibrated clip compression can be controlled by adjustment of the aneurysm clip, the application time for compression or by controlling both [12].

A compression injury model of SCI has also been produced using modified surgical forceps. Blight developed this technique to produced lateral spinal compression injury in the guinea pig [60]. These calibrated forceps compression produced a larger volume of tissue compression and displacement of spinal column as compare to aneurysm clip compression. Taken together compression models of SCI are highly reproducible and useful to study the mechanism of pathophysiology following SCI, and are used to develop potential therapies to protect the spinal tissue from secondary damage after injury.

\section{Transection}

In animal models of transection injuries, the transection is generally performed manually to either completely or partially severe the spinal cord. With incomplete models, one can severe both ascending and descending axonal pathways in specific area of 
spinal cord white matter i.e., hemisection, dorsal hemisection, lateral hemisection, dorsal quadrant. Transection models of SCI are less clinically relevant to human SCI compared to contusion injuries, as transection injuries are rarely seen in clinics [12]. Transection models of SCI are not useful to study the complex mechanism of pathophysiology of spinal cord or to examine the effect of neuroprotective strategies. Transection models have become popular and useful to study the functional recovery of specific axonal pathways, axon regeneration, cell transplantation, multiple treatment in combination or alone, biomaterial, drugs and growth factors [61-64]. The injury in this model can be induced without use of any special device.

\section{Chemical-Mediated Spinal Cord Injury}

\section{Photochemical ischemia model of SCI}

An ischemia model of SCI was first developed in rabbits [65]. This model was produced by occlusion of the abdominal aorta just below the renal arteries. Unfortunately, the spinal arterial system of rabbits is segmental and unlike that of humans and rats. In the latter, it is not possible to produce local ischemia in the spinal cord with occlusion of the aorta $[66,67]$. Moreover, this model was invasive and required abdominal surgery to ligate the abdominal aorta to interrupt the blood flow [66]. The model was refined to produce local ischemia by photochemically-produced blood clots in rats $[68,69]$. In this model, the photosensitive dye rose Bengal or erythrosine B is injected intravenously and enters the systemic circulation [69-71]. The spinal cord is irradiated with a laser light, and this laser light interacts with rose Bengal or erythrosine $\mathrm{B}$ dye, which activates the dye, inducing endothelial damage with platelet activation and thrombosis, resulting in local blood flow interruption. The laser light-dye interactions induces primary microvascular occlusion and produces an ischemia model of SCI [68-71]. This model of SCI is highly reproducible, minimally invasive and represents the ischemic component of SCI [12,70]. Moreover, unlike other models of SCI, i.e., contusion, compression and transection, the ischemia model of SCI does not require laminectomy, thus reducing collateral damage to the spinal cord $[12,68]$. The major disadvantage of photochemically induced ischemia is that this type of injury in not clinically relevant to SCI. In addition, the size and volume of the lesion are difficult to control in this injury model [72]. This model allows the study of the secondary spinal tissue damage as a result of ischemia.

\section{Chemical excitotoxicity model of SCI}

Traumatic SCI causes the release of Excitatory Amino Acids (EAAs) from neurons and the concentration of these EAAs rapidly rises to produce excitotoxicity. This excitotoxicity causes neuronal cell death and plays a major role in gray and white matter pathology [12,73]. Animal models have been developed to study the contribution of excitotoxicity to the secondary injury phase in traumatic SCI. The excitotoxic model of SCI can be produced by the administration of EAAs such as glutamate, aspartate, N-methyl-D-aspartate (NMDA), or a-amino-3-hy; droxy-5-methyl-4-isoxazole Propionic Acid (AMPA) receptor agonist kainate. Administration of these chemicals into the spinal cord causes the death of both oligodendrocytes and neurons. Application of kainate or quisqualic acid, both agonists of AMPA receptors, induces degeneration of gray matter [12,74-76].

Applications of chemicals other than EAAs have also been used to induce spinal injury. Administration of the free redical peroxynitrite, calpain, hydrogen peroxide or the microglia activator zymosan into spinal cord causes damage to lipids and proteins, cell death of oligodendrocytes and neurons, and produces inflammation that ultimately develops into the pathology similar to that seen in secondary phase of traumatic SCI [77-79]. In addition, micro-injection of lysolecithin or ethidium bromide causes demyelination and death of oligodendrocytes [12].

Chemical models of SCI are not physically invasive and are useful to study the pathophysiology of secondary mechanisms of Spinal Cord Injury, because they produce inflammation, demyelination of axons, cell death of both oligodendrocytes and neurons, and degeneration of both gray and white matter in spinal cord, all events which occur in secondary phase of traumatic SCI. Chemical models of SCI allow to study the contribution of excitotoxicity to the secondary injury phase in traumatic SCI.

\section{Conclusion}

Spinal Cord Injury is a spontaneous, unpredictable event and there is no single animal model that has dominated in the field SCI research to completely mimic the pathophysiological events observed following SCI in humans each model has advantages and disadvantages. These animal models of SCI may be useful to understand the mechanisms of SCI and used to examine the effect of potential therapeutic agents to protect neuronal and non-neuronal cell loss due to secondary injury. Rat models of SCI have provided valuable information to understand the mechanisms involved in SCI. These animal models of SCI helpful to develop new potential therapeutic strategies and pharmacological testing for an effective treatment for SCI patients which ultimately improve functional recovery in persons with chronic SCI.

\section{References}

1. Tetzlaff WK, Fouad K, Kwon B (2009) Be careful what you train for. Nat Neurosci 12: 1077-1079.

2. Tofte N, Nielsen AC, Trøstrup H, Andersen CB, Von Linstow M, et al. (2017) Chronic urinary tract infections in patients with spinal cord lesions - biofilm infection with need for long-term antibiotic treatment. APMIS 125: 385-391.

3. Winslow C, Rozovsky J (2003) Effect of spinal cord injury on the respiratory system. Am J Phys Med Rehabil 82: 803-814.

4. Opperman EA, Buchholz AC, Darlington GA, Martin Ginis KA (2010) Dietary supplement use in the spinal cord injury population. Spinal Cord 48: 60-64. 
Citation: Hassan A (2018) Rat Models of Spinal Cord Injury Provide Valuable Insight to Understand the Mechanism and Pathophysiology of Spinal Cord Injury. Curr Adv Neurol Neurol Disord 2018: 1-6. DOI: https://doi.org/10.29199/2637-6997/CANN-102018.

5. Sipski M, Alexander CJ, Gomez-Marin O (2006) Effects of level and degree of spinal cord injury on male orgasm. Spinal Cord 44: 798804.

6. Francis K (2007) Physiology and management of bladder and bowel continence following spinal cord injury. Ostomy Wound Manage 53: 18-27.

7. Mayr W, Krenn M, Dimitrijevic MR (2016) Motor Control of Human Spinal Cord Disconnected from the Brain and Under External Movement. Adv Exp Med Biol 957: 159-171.

8. Kirshblum S, Millis S, McKinley W, Tulsky D (2004) Late neurologic recovery after traumatic spinal cord injury. Arch Phys Med Rehabil 85: 1811-1817.

9. Liu NK, Zhang YP, Titsworth WL, Jiang X, Han S, et al. (2006) A novel role of phospholipase A2 in mediating spinal cord secondary injury. Ann Neurol 59: 606-619.

10. Tator CH, Fehlings MG (1991) Review of the secondary injury theory of acute spinal cord trauma with emphasis on vascular mechanisms. J Neurosurg 75: 15-26.

11. Zhang N, Yin $Y, X u$ S, Wu Y, Chen W (2012) Inflammation \& apoptosis in spinal cord injury. Indian J Med Res 135: 287-296.

12. Onifer SM, Rabchevsky AG, Scheff SW (2007) Rat models of traumatic spinal cord injury to assess motor recovery. ILAR J 48: 385395.

13. Kwon BK, Tetzlaff W, Grauer JN, Beiner J, Vaccaro AR (2004) Pathophysiology and pharmacologic treatment of acute spinal cord injury. Spine J 4: 451-464.

14. Blight A (2000) Animal Models of Spinal Cord Injury. Topics in Spinal Cord Injury Rehabilitation 6: 1-13.

15. Choo AM, Liu J, Liu Z, Dvorak M, Tetzlaff W, et al. (2009) Modeling spinal cord contusion, dislocation, and distraction: characterization of vertebral clamps, injury severities, and node of Ranvier deformations. J Neurosci Methods 181: 6-17.

16. Choo AM, Liu J, Lam CK, Dvorak M, Tetzlaff W, et al. (2007) Contusion, dislocation, and distraction: primary hemorrhage and membrane permeability in distinct mechanisms of spinal cord injury. $J$ Neurosurg Spine 6: 255-266.

17. Rowland JW, Hawryluk GW, Kwon B, Fehlings MG (2008) Current status of acute spinal cord injury pathophysiology and emerging therapies: promise on the horizon. Neurosurg Focus 25.

18. Sekhon LH, Fehlings MG (2001) Epidemiology, demographics, and pathophysiology of acute spinal cord injury. Spine (Phila Pa 1976) 26: 2-12.

19. Wallace MC, Tator CH, Frazee P (1986) Relationship between posttraumatic ischemia and hemorrhage in the injured rat spinal cord as shown by colloidal carbon angiography. Neurosurgery 18: 433-739.

20. Dohrmann GJ, Allen WE (1975) Microcirculation of traumatized spinal cord. A correlation of microangiography and blood flow patterns in transitory and permanent paraplegia. J Trauma 15: 1003-1013.

21. Nemecek S (1978) Morphological evidence of microcirculatory disturbances in experimental spinal cord trauma. Adv Neurol 20: 395405.

22. de la Torre JC (1981) Spinal cord injury. Review of basic and applied research. Spine (Phila Pa 1976) 6: 315-335.

23. Tator CH, Koyanagi I (1997) Vascular mechanisms in the pathophysiology of human spinal cord injury. J Neurosurg 86: 483-492.

24. Bareyre FM, Schwab ME (2003) Inflammation, degeneration and regeneration in the injured spinal cord: insights from DNA microarrays. Trends Neurosci 26: 555-563.
25. Popovich PG, Yu JY, Whitacre CC (1997) Spinal cord neuropathology in rat experimental autoimmune encephalomyelitis: modulation by oral administration of myelin basic protein. J Neuropathol Exp Neurol 56: 1323-1338.

26. Choi DW (1988) Calcium-mediated neurotoxicity: relationship to specific channel types and role in ischemic damage. Trends Neurosci 11: 465-469.

27. Kusters JM, Dernison MM, van Meerwijk WPM, Ypey DL, Theuvenet APR, et al. (2005) Stabilizing role of calcium store-dependent plasma membrane calcium channels in action-potential firing and intracellular calcium oscillations. Biophys J 89: 3741-3756.

28. Wells JE, Hurlbert RJ, Fehlings MG, Yong VW (2003) Neuroprotection by minocycline facilitates significant recovery from spinal cord injury in mice. Brain 126: 1628-1637.

29. Mody I, MacDonald JF (1995) NMDA receptor-dependent excitotoxicity: the role of intracellular $\mathrm{Ca} 2+$ release. Trends Pharmacol Sci 16: 356-359.

30. Dusart I, Schwab ME (1994) Secondary cell death and the inflammatory reaction after dorsal hemisection of the rat spinal cord. Eur J Neurosci 6: 712-724.

31. Emery E, Aldana P, Bunge MB, Puckett W, Srinivasan A, et al. (1998) Apoptosis after traumatic human spinal cord injury. J Neurosurg 89: 911-920.

32. Mattson MP (2000) Apoptosis in neurodegenerative disorders. Nat Rev Mol Cell Biol 1: 120-129.

33. Wada S, Yone K, Ishidou Y, Nagamine T, Nakahara S, et al. (1999) Apoptosis following spinal cord injury in rats and preventative effect of $\mathrm{N}$-methyl-D-aspartate receptor antagonist. J Neurosurg 91: 98104.

34. Byrnes KR, Stoica BA, Fricke S, Di Giovanni S, Faden A (2007) Cell cycle activation contributes to post-mitotic cell death and secondary damage after spinal cord injury. Brain 130: 2977-2992.

35. Crowe MJ, Bresnahan JC, Shuman SL, Masters JN, Crowe MS (1997) Apoptosis and delayed degeneration after spinal cord injury in rats and monkeys. Nat Med 3: 73-76.

36. Whalley K, O'Neill P, Ferretti P (2006) Changes in response to spinal cord injury with development: vascularization, hemorrhage and apoptosis. Neuroscience 137: 821-32.

37. Titsworth WL, Cheng X, Ke Y, Deng L, Burckardt KA, et al. (2009) Differential expression of SPLA2 following spinal cord injury and a functional role for SPLA2-IIA in mediating oligodendrocyte death. Glia 57: 1521-1537.

38. Barres BA, Jacobson MD, Schmid R, Sendtner M, Raff MC (1993) Does oligodendrocyte survival depend on axons? Curr Biol 3: 489497.

39. Soini Y, Kahlos K, Sormunen R, Säily M, Mäntymaa P, et al. (2005) Activation and relocalization of caspase 3 during the apoptotic cascade of human mesothelioma cells. APMIS 113: 426-435.

40. Springer JE, Azbill RD, Knapp PE (1999) Activation of the caspase-3 apoptotic cascade in traumatic spinal cord injury. Nat Med 5: 943946.

41. Sharif-Alhoseini M, Khormali M, Rezaei M, Safdarian M, Hajighadery A, et al. (2017) Animal models of spinal cord injury: a systematic review. Spinal Cord 55: 714-721.

42. Geissler SA, Schmidt CE, Schallert T (2013) Rodent Models and Behavioral Outcomes of Cervical Spinal Cord Injury. J Spine 4: 001.

43. Allen AR (1911) Surgery of experimental lesion of spinal cord equivalent to crush injury of fracture dislocation of spinal column: A preliminary report. JAMA LVII: 878-880. 
Citation: Hassan A (2018) Rat Models of Spinal Cord Injury Provide Valuable Insight to Understand the Mechanism and Pathophysiology of Spinal Cord Injury. Curr Adv Neurol Neurol Disord 2018: 1-6.

44. Wrathall JR, Pettegrew RK, Harvey F (1985) Spinal cord contusion in the rat: production of graded, reproducible, injury groups. Exp Neurol 88: 108-122.

45. Gruner JA (1992) A monitored contusion model of spinal cord injury in the rat. J Neurotrauma 9: 123-126.

46. Noyes DH (1987) Electromechanical impactor for producing experimental spinal cord injury in animals. Med Biol Eng Comput 25: 335340.

47. Kwon B, Hillyer J, Tetzlaff W (2010) Translational research in spinal cord injury: a survey of opinion from the $\mathrm{SCl}$ community. J Neurotrauma 27: 21-33.

48. Norenberg MD, Smith J, Marcillo A (2004) The pathology of human spinal cord injury: defining the problems. J Neurotrauma 21: 429440.

49. Nobunaga Al, Go BK, Karunas RB (1999) Recent demographic and injury trends in people served by the Model Spinal Cord Injury Care Systems. Arch Phys Med Rehabil 80: 1372-1382.

50. Fukuda S, Nakamura T, Kishigami Y, Endo K, Azuma T, et al. (2005) New canine spinal cord injury model free from laminectomy. Brain Res Brain Res Protoc 14: 171-180.

51. Talac R, Friedman JA, Moore MJ, Lu L, Jabbari E, et al. (2004) Animal models of spinal cord injury for evaluation of tissue engineering treatment strategies. Biomaterials 25: 1505-1510.

52. Lee DH, Lee JK (2013) Animal models of axon regeneration after spinal cord injury. Neurosci Bull 29: 436-444.

53. Abdullahi D, Annuar AA, Mohamad M, Aziz I, Sanusi J (2017) Experimental spinal cord trauma: a review of mechanically induced spinal cord injury in rat models. Rev Neurosci 28: 15-20.

54. Rivlin AS, Tator CH (1978) Effect of duration of acute spinal cord compression in a new acute cord injury model in the rat. Surg Neurol 10: 38-43.

55. Tarlov IM, Klinger H, Vitale S (1953) Spinal cord compression studies. I. Experimental techniques to produce acute and gradual compression. AMA Arch Neurol Psychiatry 70: 813-819.

56. Vanický I, Urdzíková L, Saganová K, Cízková D, Gálik J (2001) A simple and reproducible model of spinal cord injury induced by epidural balloon inflation in the rat. J Neurotrauma 18: 1399-1407.

57. Martin D, Schoenen J, Delrée P, Gilson V, Rogister B, et al. (1992) Experimental acute traumatic injury of the adult rat spinal cord by a subdural inflatable balloon: methodology, behavioral analysis, and histopathology. J Neurosci Res 32: 539-550.

58. Rivlin AS, Tator CH (1978) Regional spinal cord blood flow in rats after severe cord trauma. J Neurosurg 49: 844-853.

59. Fehlings MG, Tator $\mathrm{CH}$, Linden RD (1989) The relationships among the severity of spinal cord injury, motor and somatosensory evoked potentials and spinal cord blood flow. Electroencephalogr Clin Neurophysiol 74: 241-259.

60. Blight AR (1991) Morphometric analysis of a model of spinal cord injury in guinea pigs, with behavioral evidence of delayed secondary pathology. J Neurol Sci 103: 156-171.

61. Bregman BS, Coumans JV, Dai HN, Kuhn PL, Lynskey J, et al. (2002) Transplants and neurotrophic factors increase regeneration and recovery of function after spinal cord injury. Prog Brain Res 137: 257-273.

62. Shumsky JS, Tobias CA, Tumolo M, Long WD, Giszter SF, et al. (2003) Delayed transplantation of fibroblasts genetically modified to secrete BDNF and NT-3 into a spinal cord injury site is associated with limited recovery of function. Exp Neurol 184: 114-130.
63. Tobias CA, Shumsky JS, Shibata M, Tuszynski MH, Fischer I, et al. (2003) Delayed grafting of BDNF and NT-3 producing fibroblasts into the injured spinal cord stimulates sprouting, partially rescues axotomized red nucleus neurons from loss and atrophy, and provides limited regeneration. Exp Neurol 184: 97-113.

64. Knudsen EB, Moxon KA, Sturgis EB, Shumsky JS (2011) Skilled hindlimb reaching task in rats as a platform for a brain-machine interface to restore motor function after complete spinal cord injury. Conf Proc IEEE Eng Med Biol Soc 2011: 6315-6318.

65. DeGirolami U, Zivin JA (1982) Neuropathology of experimental spinal cord ischemia in the rabbit. J Neuropathol Exp Neurol 41: 129149.

66. Kanellopoulos GK, Kato H, Hsu CY, Kouchoukos NT (1997) Spinal cord ischemic injury. Development of a new model in the rat. Stroke 28: 2532-2538.

67. Fazio V (1971) Vascular pathology of the spinal cord. In: Minkler $\mathrm{J}$ (ed.). Pathology of the Nervous System. McGraw-Hill Publishing Co, NY, USA.

68. Prado R, Dietrich WD, Watson BD, Ginsberg MD, Green BA (1987) Photochemically induced graded spinal cord infarction. Behavioral, electrophysiological, and morphological correlates. J Neurosurg 67: 745-753.

69. Watson BD, Prado R, Dietrich WD, Ginsberg MD, Green BA (1986) Photochemically induced spinal cord injury in the rat. Brain Res 367: 296-300.

70. Hao JX, Xu XJ, Aldskogius H, Seiger A, Wiesenfeld-Hallin Z (1991) Allodynia-like effects in rat after ischaemic spinal cord injury photochemically induced by laser irradiation. Pain 45: 175-185.

71. Cameron T, Prado R, Watson BD, Gonzalez-Carvajal M, Holets VR (1990) Photochemically induced cystic lesion in the rat spinal cord. I. Behavioral and morphological analysis. Exp Neurol 109: 214-223.

72. Kundi S, Bicknell R, Ahmed Z (2013) Spinal cord injury: Current mammalian models. Neuroscience International 4: 1-12.

73. Park E, Velumian AA, Fehlings MG (2004) The role of excitotoxicity in secondary mechanisms of spinal cord injury: a review with an emphasis on the implications for white matter degeneration. J Neurotrauma 21: 754-774.

74. Magnuson DS, Trinder TC, Zhang YP, Burke D, Morassutti DJ, et al. (1999) Comparing deficits following excitotoxic and contusion injuries in the thoracic and lumbar spinal cord of the adult rat. Exp Neurol 156: 191-204.

75. Onifer SM, Cannon AB, Whittemore SR (1997) Altered differentiation of CNS neural progenitor cells after transplantation into the injured adult rat spinal cord. Cell Transplant 6: 327-338.

76. Yezierski RP, Santana M, Park SH, Madsen PW (1993) Neuronal degeneration and spinal cavitation following intraspinal injections of quisqualic acid in the rat. J Neurotrauma 10: 445-456.

77. Hall ED (2001) Pharmacological treatment of acute spinal cord injury: how do we build on past success? J Spinal Cord Med 24: 142146.

78. Liu D (1993) Generation and detection of hydroxyl radical in vivo in rat spinal cord by microdialysis administration of Fenton's reagents and microdialysis sampling. J Biochem Biophys Methods 27: 281291.

79. Popovich PG, Guan Z, McGaughy V, Fisher L, Hickey WF, et al. (2002) The neuropathological and behavioral consequences of intraspinal microglial/macrophage activation. J Neuropathol Exp Neurol 61: 623-633. 